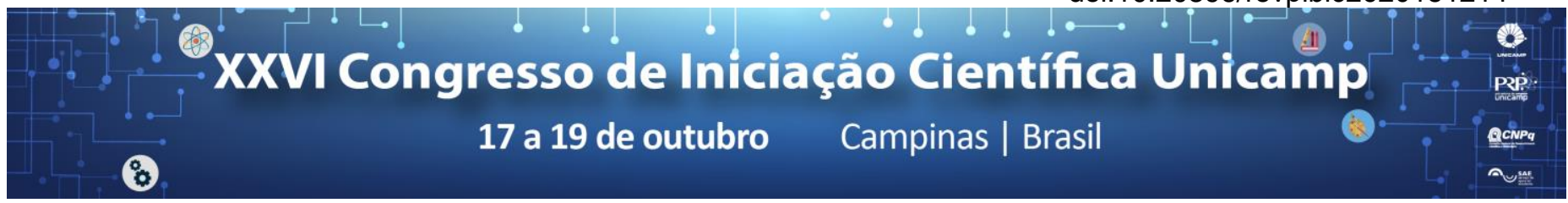

\title{
Instrumentação para medição on-line da concentração de cristais no gelo líquido
}

\section{Rennan YieYassu Nishimori, Vivaldo Silveira Junior, Ricardo Santos Nascimento}

\section{Resumo}

Este trabalho tem como objetivo desenvolver um método de medição da concentração de cristais no gelo líquido de maneira rápida e precisa para ser implementada em linha.

\section{Palavras-chave: \\ Gelo Líquido, Concentração de Cristais, Ultrassom}

\section{Introdução}

O gelo líquido é uma tecnologia nova que tem mostrado grande potencial energético, pela sua capacidade de transportar energia como fluido térmico e armazenar "frio" por energia latente de fusão [1]. O objetivo desse trabalho foi desenvolver um dispositivo capaz de mensurar a concentração de cristais de gelo em solução de gelo líquido.

Várias propriedades termo físicas do gelo líquido podem ser usadas para determinar a concentração do gelo, sabendo se que as propriedades do gelo líquido diferem significativamente do gelo puro. As propriedades termo físicas do gelo líquido podem, em muitos casos, serem deduzidas por ponderação linear das propriedades do gelo e do líquido [2] [3]. Nesse trabalho foram utilizados dois princípios de medições: velocidade do som do fluido, condutividade elétrica.

As medições foram realizadas com a solução em batelada, ou seja, sem vazão mássica e com solução modelo com particulados em escoamento.

\section{Resultados e Discussão}

Os experimentos realizados em batelada tiveram como objetivo a leitura indireta da concentração de gelo por meio da concentração do aditivo anticongelante no fluido transportador.

Todas as medições de concentração utilizando o ultrassom e o condutivímetro foram correlacionadas com o método de balanço de energia que é o método mais confiável.

As figuras 1 e 2 são os resultados obtidos nas medições em batelada

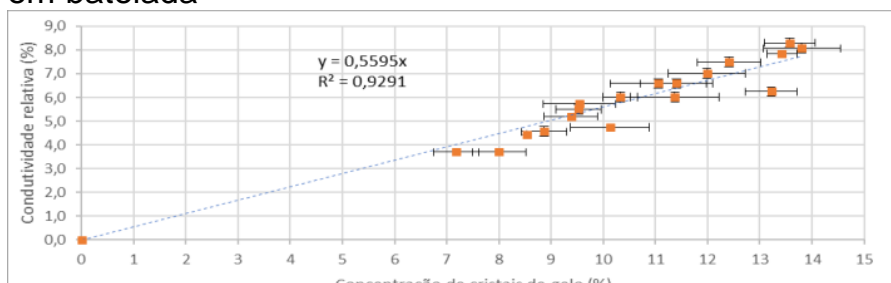

Figura 1. Gráfico de dispersão da condutividade elétrica relativa em solução de Gelo líquido, com curva de tendência Linear e sua respectiva equação de regressão.

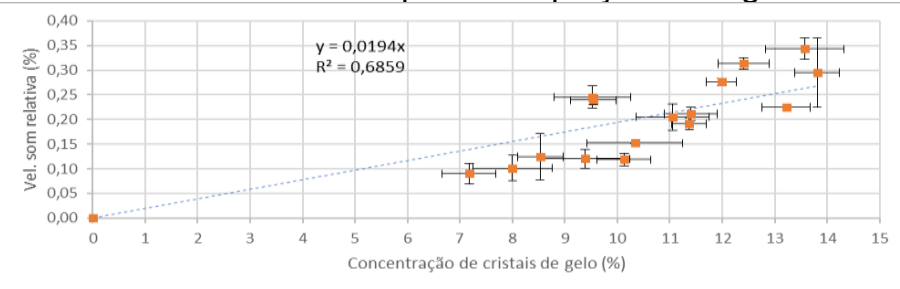

Figura 2. Gráfico de dispersão da velocidade do som relativo em solução de Gelo líquido, com curva de tendência linear e sua respectiva equação de regressão.

Para verificar a viabilidade do equipamento para medição on-line, foi feita uma análise usando o ultrassom em linha e uma solução modelo com diferentes concentrações de microesferas.

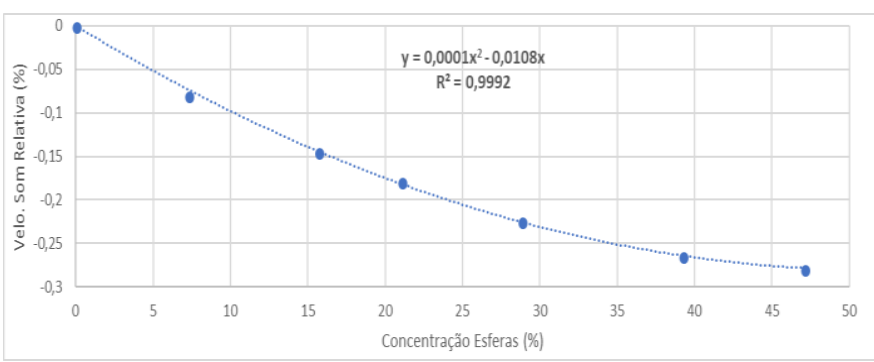

Figura 3. Gráfico de velocidade do som relativa em solução modelo com particulados em escoamento, com curva de tendência polinomial e sua respectiva equação de regressão.

\section{Conclusões}

A partir dos resultados obtidos na medição da concentração foi comprovada a viabilidade técnica do equipamento para determinar a concentração de cristais de gelo no gelo líquido em sistemas de batelada e online.

A leitura por condutividade demonstrou melhor tendência à medição da concentração de cristais de gelo, em batelada, com características lineares.

[1] KAUFFELD, M.; WANG, M. J.; GOLDSTEIN, V.; KASZA, K. E. Ice slurry applications. International Journal of Refrigeration, 33(8), 1491-1505, 2010 .

[2] TICONA, E. M. Determinação experimental do coeficiente de troca de calor em um gerador de pasta de gelo. Rio de Janeiro, RJ: Dissertação (mestrado) - Pontifícia Universidade Católica do Rio de Janeiro, Departamento de Engenharia Mecânica, 2003. Disponível em: <https://www.sciencedirect.com/science/article/pii/S0140700710001647?via\% 3Dihub>. Acesso em: 01 jun. 2017.

[3]HANSEN, T. M.; KAUFFELD, M. Measuring principles for the determination of ice concentration in ice slurry, 2001.

BELLAS, I.; TASSOU, S. A. Present and future applications of ice slurries. International Journal of Refrigeration, 28, 115-121, 2005. 